\title{
AWARENESS OF MATERNITY AND GYNECOLOGICAL NURSES TOWARDS COMPLEMENTARY AND ALTERNATIVE THERAPIES
}

Prof. Sanaa Ali Nour; Dr. Nagat Salah Shalaby; Samar Abdel Hakam Mohamed Hassan

Professor of Obstetrics and Gynecological Nursing - Faculty of Nursing - Zagazig

University; Lecturer of Maternal, Obstetrics and Gynecology Nursing - Faculty of Nursing - Port Said University; B.Sc. Nursing - Mansoura University

\begin{abstract}
Background: Nurses interest and participation in Complementary and Alternative Therapies (CATs) are increasing. Therefore, it is important for maternity nurses to be knowledgeable of the multiple CATs available and the use of these therapies by women. It is also important for nurses to keep abreast of current researches being done in this area to provide accurate information, not only to the client, but also to other health care professionals. Aim: to assess awareness of maternity and gynecologic nurses towards complementary and alternative therapies.Subject and methods: A descriptive design was utilized in this study. The Sample was including 90 nurses were participated in the current study. It was carried out at obstetric and gynecologic departments / outpatient clinics of Mansoura university hospital, and Maternal and Child Health Centers for Hai Awal and Hai Thani. Interviewed questionnaire sheet was developed by the researcher for collection of data. Results: of this study revealed that the majority of nurses utilized types of CATs personally. Most of them used herbal therapy, honey and bee products, spiritual healing and massage despite their insufficient knowledge about them.Conclusion: It was concluded from current study that the majority of nurses $(87.8 \%)$ had unsatisfactory knowledge about complementary/ alternative therapies and utilized some types of CATs e.g. herbal therapy without recognizing its correct benefit. Moreover, $(67.8 \%)$ of nurses had positive attitude towards the use of CATs. It was recommended that academic preparation of maternity nurses should be regularly updated through incorporation of CATs within their curricula.
\end{abstract}




\section{INTRODUCTION}

Complementary and Alternative therapy (CAT) has become increasingly popular in recent years and become acceptable to the general public and is increasingly used around the world. Complementary therapy is an attachment to conventional medical treatment that has been through scientific testing shows some reliability. These therapies such as; acupressure, acupuncture, and massage therapy are now often used with conventional medical care. Alternative therapy is generally considered a substance or procedure that is used in place of conventional biomedical care. (Kenyon, 2009).

As early as 1992, the American National Center for complementary and alternative medicine (NCCAM) was established for supporting this issue (Uzun \& Tan, 2004). They refer to a brood collection of therapeutic practices and products that are not considered part of conventional medicine, they are defined by its users as the methods used in preventing or treating illness, or promoting health and well-being. Although both complementary and alternative therapies refer mostly to the same modalities yet, each one of them is defined in the literature differently where complementary therapy refers to therapies that are used together with the conventional therapies, and alternative therapies denote all the therapies that are used instead of conventional therapies (NCCAM, 2008).

The NCCAM had classified them into five main domains: Alternative (whole) medical systems, Mind-Body interventions, Biologically based practices, Manipulative and body Based practices, and Energy therapy (NCCAM, 2009).

The generic term "CAT" encompasses a range of diverse therapies which vary widely in regard to evidence of safety and efficacy, and acceptance within the community. Women are the highest consumers of CAT in the general population and many continue their use during pregnancy, also midwives have a growing interest in CAT and their place in the maternity setting. (Wang \& Dezinnop, 2005; Cohen, 2007; Kenyon, 2009; Braun, Bishop, Lewith, 2010).

Research reveals the popularity of a specific modality is often dependent on the indication. For example, Bayles, (2007) found the most frequently used CAT for back pain were Chiropractic care $(51 \%)$ and massage $(98 \%)$, while popular therapies to nausea/ vomiting were herbs $(80 \%)$ and acupuncture $(40 \%)$. Common indications for the recommendation of complementary therapies generally include; labor induction and augmentation, nausea and vomiting, relaxation, back pain, anemia, malpresentation, perineal discomfort, postpartum depression and lactation problems and dysmenorrhea (Allaire \& Wells, 2009; Hording \& Foureur, 2009).

Nursing interventions is an integral component of nursing practice and a major concern for most nurses. The nurse plays a very important role in pain management through offering comfort measures and reassurance to relief anxiety. Her roles include as well, offering alternative therapies for symptoms relief, checking safety or side effects of these therapies and refer women to a physician if severe symptoms such as in-tense pain or vomiting occur regularly for 3 months or more (Rankin, 2001). 


\section{AIM OF STUDY:}

The study aims to assess awareness of maternity and gynecologic nurses toward complementary and alternative therapies.

\section{SUBJECT AND METHODS:}

\section{Design:}

A descriptive design was utilized in this study to assess the awareness of maternity and gynecologic nurses toward complementary and alternative therapies.

\section{setting:}

The sample consisted of 90 nurses worked at obstetric and gynecologic departments/ outpatient clinics of the following health care settings: Mansoura university hospital; Maternal and child health center (MCHC) for Hai Awal; Maternal and child health center for Hai Thani.

\section{Tools of Data Collection:}

consisted of Interview questionnaire sheet. This was

developed by the researcher for collection of the following data:

- Socio-demographic characteristics: such as nurse's age, level of education, and residence, position and years of experience.

- Data about the nurses' knowledge regarding CATs such as: meaning, types, uses of CATs and sources of knowledge.

- Dataaboutnurses'utilizationof ComplementaryandAlternativetherapysuchas: modalities used reasons for use, and techniques of usage.

- Nurses' attitude towards CATs: it is a likert scale format that include; statements answered on a 3 point scale of response about nurses attitudes (i.e., agree, disagree, undecided).

\section{RESULTS:}

Table (1): shows that the age of nurses ranged from 18-57 years with mean age of $36.0 \pm 8.9$. Almost three quarters $(73.3 \%)$ of the nurses have secondary nursing diploma while, $10 \%$ had technical or/bachelor degree and only $3.3 \%$ of them are postgraduate. Meanwhile, $70.0 \%$ have more than 20 years of experience; the majority $(83.3 \%)$ provides direct patient care and only $3.3 \%$ are attended training courses about CATs.

Table (2): reveals that only $3.3 \%$ of nurses know the correct definition of CATs, $15.6 \%$ recognized the types and none of them have any idea about its side effects. In total the majority of nurses $(87.8 \%)$ have unsatisfactory knowledge about complementary/alternative therapies.

According to (table 3):, almost one-third of the nurses (31.1\%) reports are received information about CATs from their relatives and friends, followed by mass media. Nearly half of them $(52.2 \%)$ preferred to have training course to be conducted by CATs specialist (88.9\%). Moreover, most of them $(82.2 \%)$ are in need of such information. 
Table (4): indicates that the majority $(81.1 \%)$ of nurses utilize herbal therapy although $56.7 \%$ recognize its correct benefit. The same patterns are partially noticed regarding the use of honey and bee products $83.3 \%$ vs. $71.1 \%$ respectively. Spiritual healing and massage are utilized by almost three quarters of nurses $75.6 \%$ and $77.8 \%$ respectively, but also they have insufficient knowledge about both of them $61.1 \%$ and $51.1 \%$ respectively. Meanwhile only $30.0 \%$ and $6.7 \%$ utilize cupping and acupuncture.

Table (5): shows that more than three fourth of nurses (77.8\%) use CATs for the relief of dysmenorrhea and almost the same percentage found it effective. However, few numbers ranged between 3-5 nurses who used CATs for treating menopausal problems. Meanwhile, only one nurse used CATs for treating infertility.

According to (table 6): half of nurses (50.0\%) use CATs for the relief of heartburn during pregnancy and partially similar proportion (41.1\%) indicated that they use them for combating nipple trauma and also depression during the postnatal period (27.7\%). All of them reported that they are effective. Few numbers used CATs for other minor discomforts related to pregnancy and puerperium such as nausea and vomiting, back pain and insufficient breast milk 19.9\%, 18.9\% and 29.9\% respectively.

Figure (1): shows that more than three fourths $(77.75 \%)$ of the nurses use herbs in management of dysmenorrhea. Meanwhile, more than one third (35\%) of them use cinnamon, 25\% use peppermint and less than one fifth (17.75\%) use anise. Nurses reporte that these types have positive effect in reduction of menstrual pain.

Figure (2): shows that half of nurses (50\%) use milk to get rid of heartburn. Less than one - fifth $(18.8 \%)$ of nurses use nigella oil $(6 \%)$ and massage $(12.8 \%)$ to alleviate back pain during their pregnancy. For management of nausea and vomiting combined with pregnancy, nurses use peppermint $(9 \%)$ and ginger ( $10.9 \%)$. Most of them $(81.6 \%)$ reports that these types are effective.

Figure (3): shows that less than three fourth $(72.1 \%)$ of the nurses use some types of CATs in management of some lactation problems. In dealing with the problem of low milk supply they use moughat, anise and fenugreek (4.9\%, $10 \%$ and $15 \%$ respectively). Meanwhile, less than one fourth (21.1\%) of the nurses use olive oil in the management of nipple trauma, they also use honey and colostrum with almost same proportion (20\%). Concerning the management of breast engorgement $1.1 \%$ of them use hot application. Almost $(71.1 \%)$ of the nurses reported that the types they used were effective

Figure (4): shows that less than one fifth (16.7\%) of nurses use milk, figs, vegetables and senna (sennamaky) as a type of diet therapy in the relief of constipation during their pregnancy. All of the nurses who used these CATs cited that they were effective.

Figure (5): shows that less than one third $(27.7 \%)$ of nurses use spiritual healing (16\%), relaxation technique $(7.7 \%)$ and yoga $(4 \%)$ in coping with postpartum depression. They reported that all these types are effective.

Assessment of nurse's attitude towards CATs is shown in table( 7): Almost three fourth of nurses $(75.6 \%)$ agree that it is a part of nurse's role and more than three fifth have a positive attitude toward its application and its associated risks $(62.2 \%$ 
and67.8\% respectively). Moreover $(67.8 \%)$ have positive attitude towards the use of CATs.

Table 1: Socio-demographic Characteristics of Nurses in the Study Sample (N=90)

\begin{tabular}{|l|c|c||}
\hline & Frequency & Percent \\
\hline Age: & 56 & 62.2 \\
440 & 34 & 37.8 \\
Ra+ & $18.0-57.0$ & \\
Mean \pm SD & $36.0 \pm 8.9$ & \\
Median & 35.50 & \\
\hline Nursing qualification: & & \\
Secondary nursing diploma & 66 & 73.3 \\
Specialty diploma & 3 & 3.3 \\
Technical institute diploma & 9 & 10.0 \\
Bachelor & 9 & 10.0 \\
Postgraduate & 3 & 3.3 \\
\hline Experience years (current) & & \\
$<20$ & 27 & 30.0 \\
20+ & 63 & 70.0 \\
Range & $0.0-40.0$ & \\
Mean \pm SD & $14.1 \pm 9.7$ & \\
Median & 12.00 & \\
\hline Job type: & & \\
Direct care & 75 & 83.3 \\
Administration & 15 & 16.7 \\
\hline Attended training courses of CATs & 3 & 3.3 \\
\hline
\end{tabular}

Table 2: Nurses' knowledge of Complementary/Alternative Therapies and their Side effects $(\mathrm{N}=90)$.

\begin{tabular}{||l|c|c||}
\hline \multicolumn{1}{|c|}{ Knowledge } & Frequency & Percent \\
\hline $\begin{array}{l}\text { Definition of Complementary treatment / Alternative } \\
\text { treatment }\end{array}$ & 3 & 3.3 \\
Types of complementary/alternative treatment in Ob/Gyne & 14 & 15.6 \\
Side effects of complementary/alternative treatment & 0 & 0.0 \\
Total: & 11 & 12.2 \\
$\quad$ Satisfactory & 79 & 87.8 \\
\hline \multicolumn{2}{|c||}{} \\
\hline
\end{tabular}


Table (3): Sources of Information about Complementary /Alternative Therapies as reported by Nurses $(\mathrm{N}=90)$.

\begin{tabular}{||l|c|c||}
\hline & Frequency & Percent \\
\hline Sources of information: & 20 & 22.2 \\
Books/journals & 22 & 24.4 \\
Internet & 26 & 28.9 \\
Common information & 5 & 5.6 \\
Traditional healer & 28 & 31.1 \\
Relatives/friends & 6 & 6.7 \\
Commercials & 12 & 13.3 \\
physician & 23 & 25.6 \\
Peers & 3 & 3.3 \\
Training courses & & \\
\hline Preferred methods : & 25 & 27.8 \\
Lectures & 47 & 52.2 \\
Courses & 17 & 18.9 \\
Journals & 2 & 2.2 \\
Studies & 8 & 8.9 \\
Internet & & \\
\hline Preferred Person: & 7 & 7.8 \\
Physician & 3 & 3.3 \\
Nurse & 80 & 88.9 \\
CAT specialist & & \\
\hline Need more information & 74 & 82.2 \\
\hline No & & \\
Yes & & 17.8 \\
\hline \hline
\end{tabular}

Table (4): Nurses' awareness about the use of Complementary/Alternative therapies and their ability to use them $(\mathrm{N}=90)$.

\begin{tabular}{||l|c|c|c|c||}
\hline \multirow{2}{*}{\multicolumn{1}{|c|}{ Items }} & \multicolumn{2}{c|}{ Awareness } & \multicolumn{2}{c|}{ Ability to use } \\
\cline { 2 - 6 } & No. & $\mathbf{\%}$ & No. & $\boldsymbol{\%}$ \\
\hline Honey and Bee products & 64 & 71.1 & 75 & 83.3 \\
\hline Spiritual healing & 55 & 61.1 & 68 & 75.6 \\
\hline Herbal therapy & 51 & 56.7 & 73 & 81.1 \\
\hline Massage & 46 & 51.1 & 70 & 77.8 \\
\hline Cupping & 30 & 33.3 & 27 & 30.0 \\
\hline
\end{tabular}


Table (5): Using and Effectiveness of Complementary/Alternative therapies in the management of some disorders related to gynecology as reported by the studied nurses $(\mathrm{N}=90)$.

\begin{tabular}{||l|c|c|c|c||}
\hline \multicolumn{2}{|c|}{ Gynecological problems } & \multicolumn{2}{c|}{ USING } & \multicolumn{2}{c|}{ Effectiveness } \\
\cline { 2 - 6 } & NO & $\mathbf{\%}$ & NO & $\mathbf{\%}$ \\
\hline Dysmenorrhea & 70 & 77.8 & 68 & 75.6 \\
\hline Vaginitis & 10 & 11.1 & 10 & 11.1 \\
\hline $\begin{array}{l}\text { Menopausal problems "hot flushes, headache } \\
\text { and insomnia" }\end{array}$ & 3 & 3.3 & 3 & 3.3 \\
\hline Infertility & 1 & 1.1 & 1 & 1.1 \\
\hline
\end{tabular}

Table (6): Using and effectiveness of Complementary/Alternative therapies in the management of some disorders related to Obstetrics as reported by the studied nurses $(\mathrm{N}=90)$.

\begin{tabular}{||l|c|c|c|c||}
\hline \multicolumn{1}{|c|}{ Obstetric problems } & USING & \% & Effectiveness & $\%$ \\
\hline Nausea /Vomiting & 18 & 19.9 & 16 & 17.8 \\
\hline Constipation & 15 & 16.7 & 15 & 16.7 \\
\hline Back pain & 17 & 18.9 & 17 & 18.9 \\
\hline Heartburn & 45 & 50 & 40 & 45 \\
\hline Breast engorgement & 1 & 1.1 & 1 & 1.1 \\
\hline Nipple trauma & 37 & 41.1 & 37 & 41.1 \\
\hline Low milk flow & 27 & 29.9 & 26 & 28.9 \\
\hline Postpartum depression & 25 & 27.7 & 25 & 27.7 \\
\hline
\end{tabular}




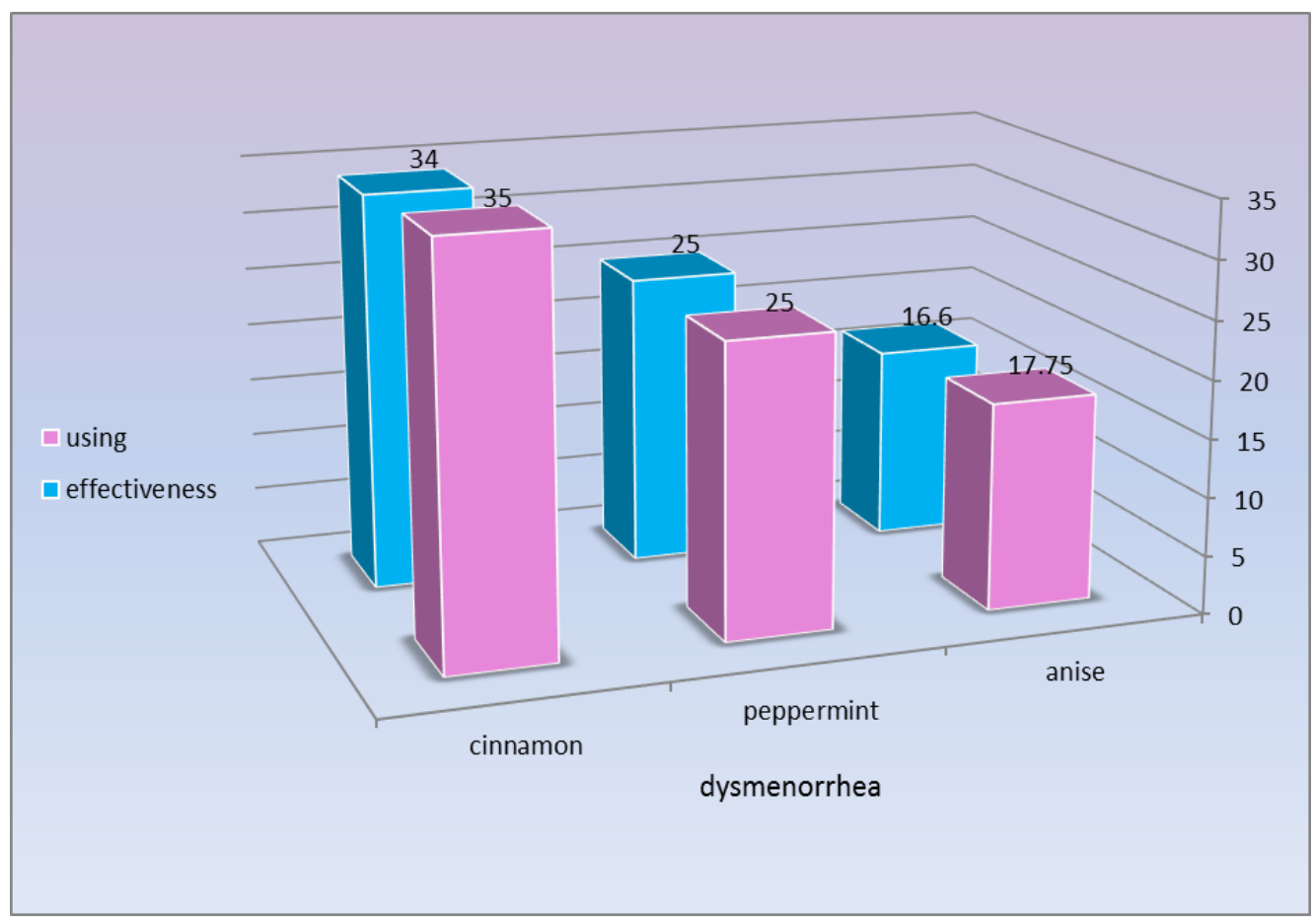

Figure (1):Types of CATs that are used by nurses in management of dysmenorrhea.

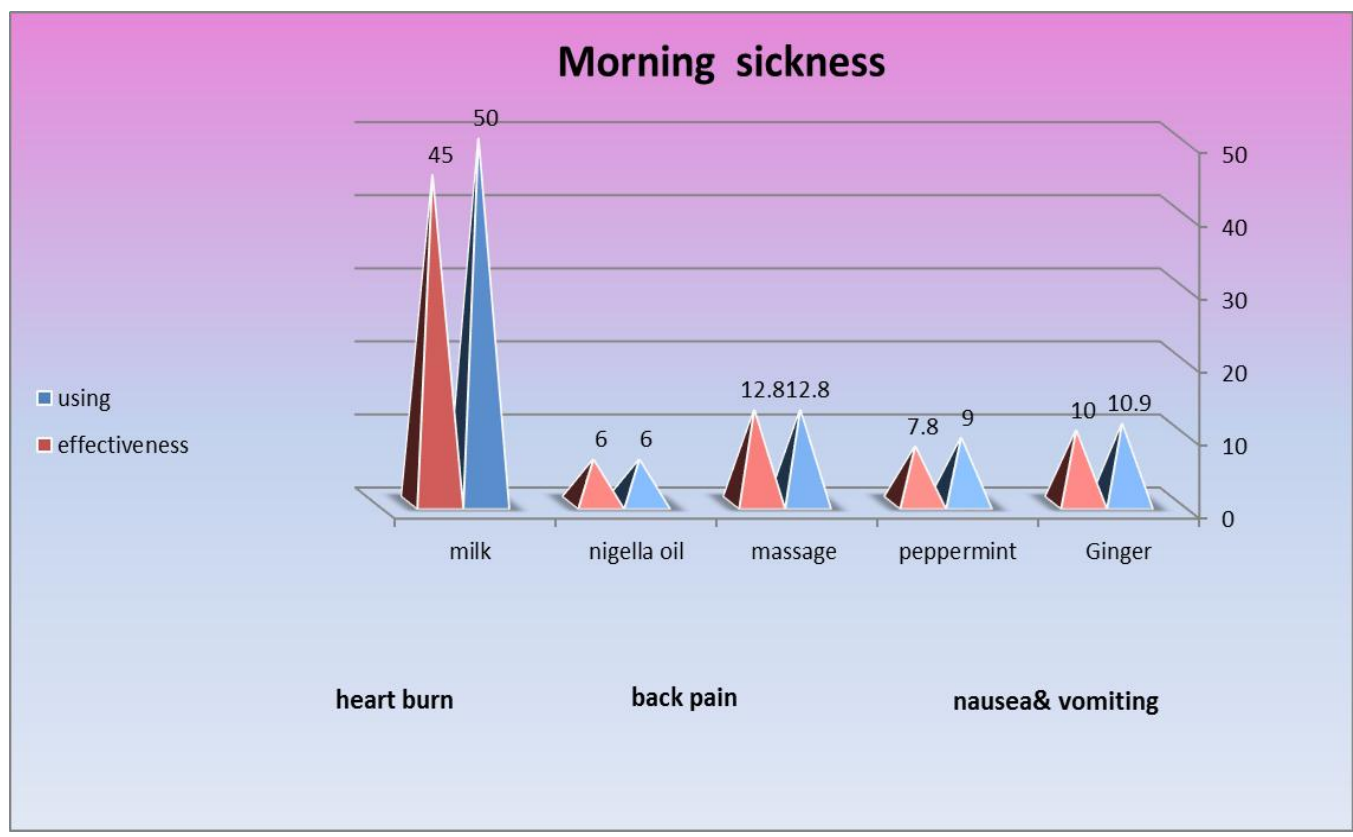

Figure 2: Types of CATs that are used by Nurses in Management of nausea \& vomiting, back pain and heart burn during pregnancy. 


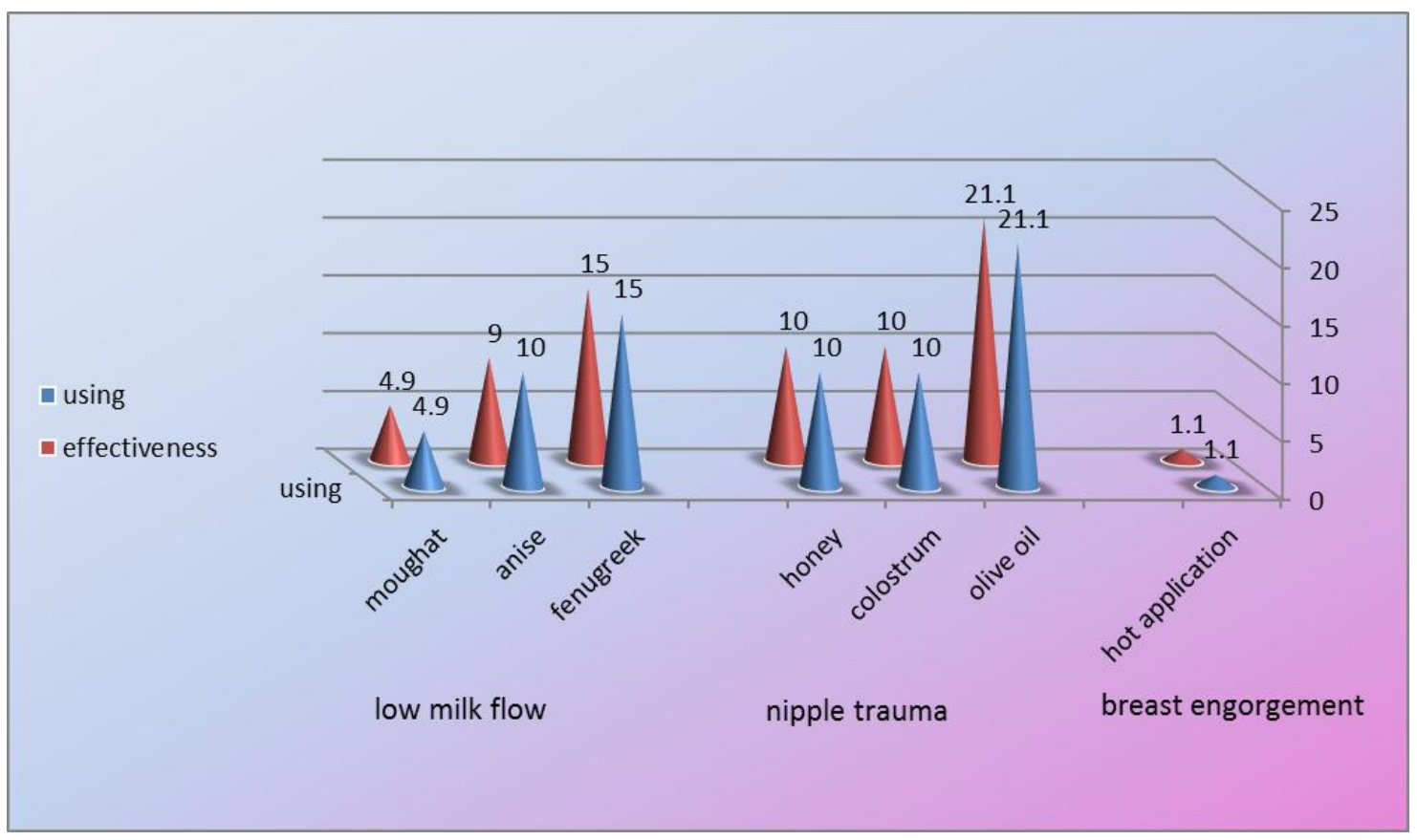

Figure (3): Types of CATs that are used by nurses in management of some lactation problems.

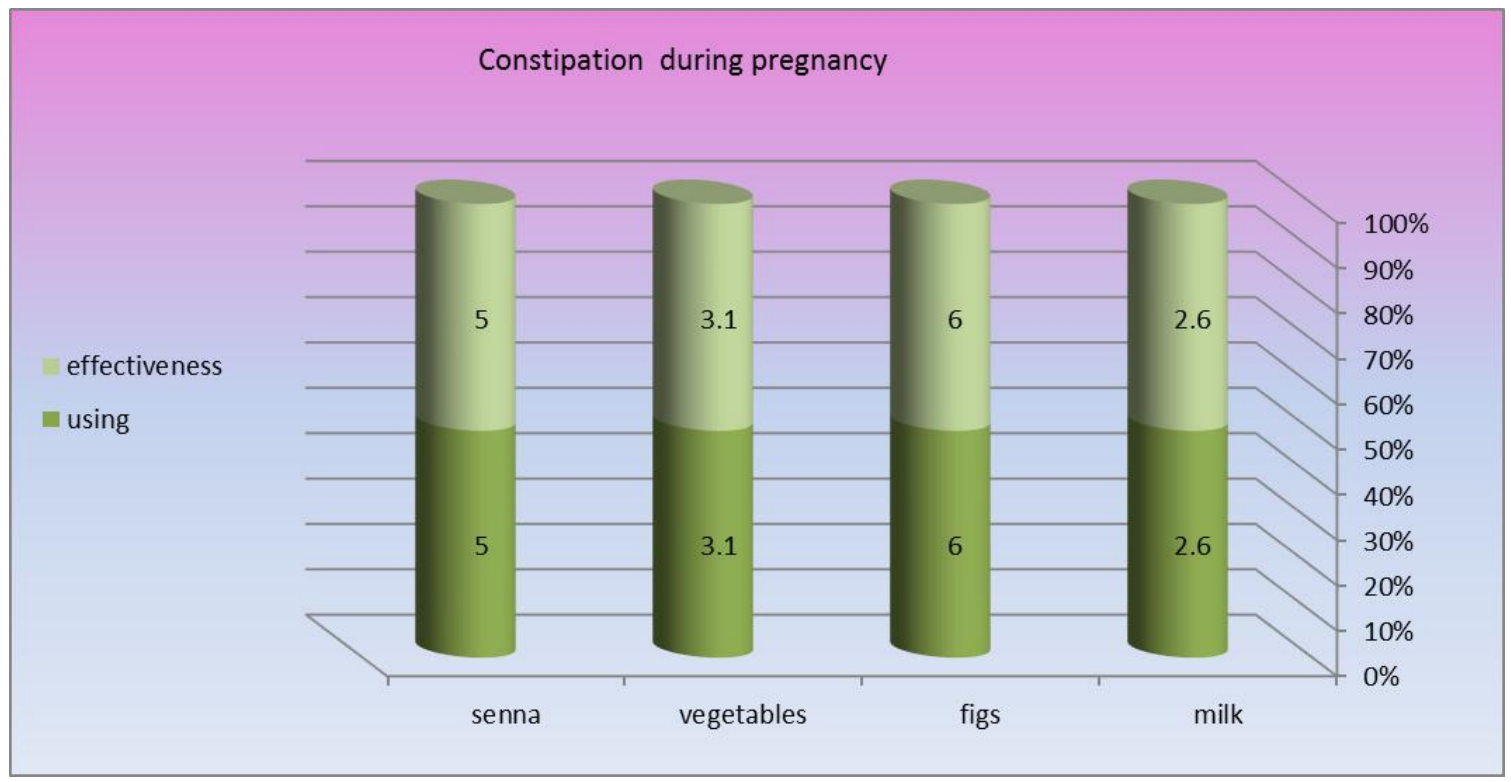

Figure (4): Types of CATs that are used by Nurses in Management of Constipation during Pregnancy 


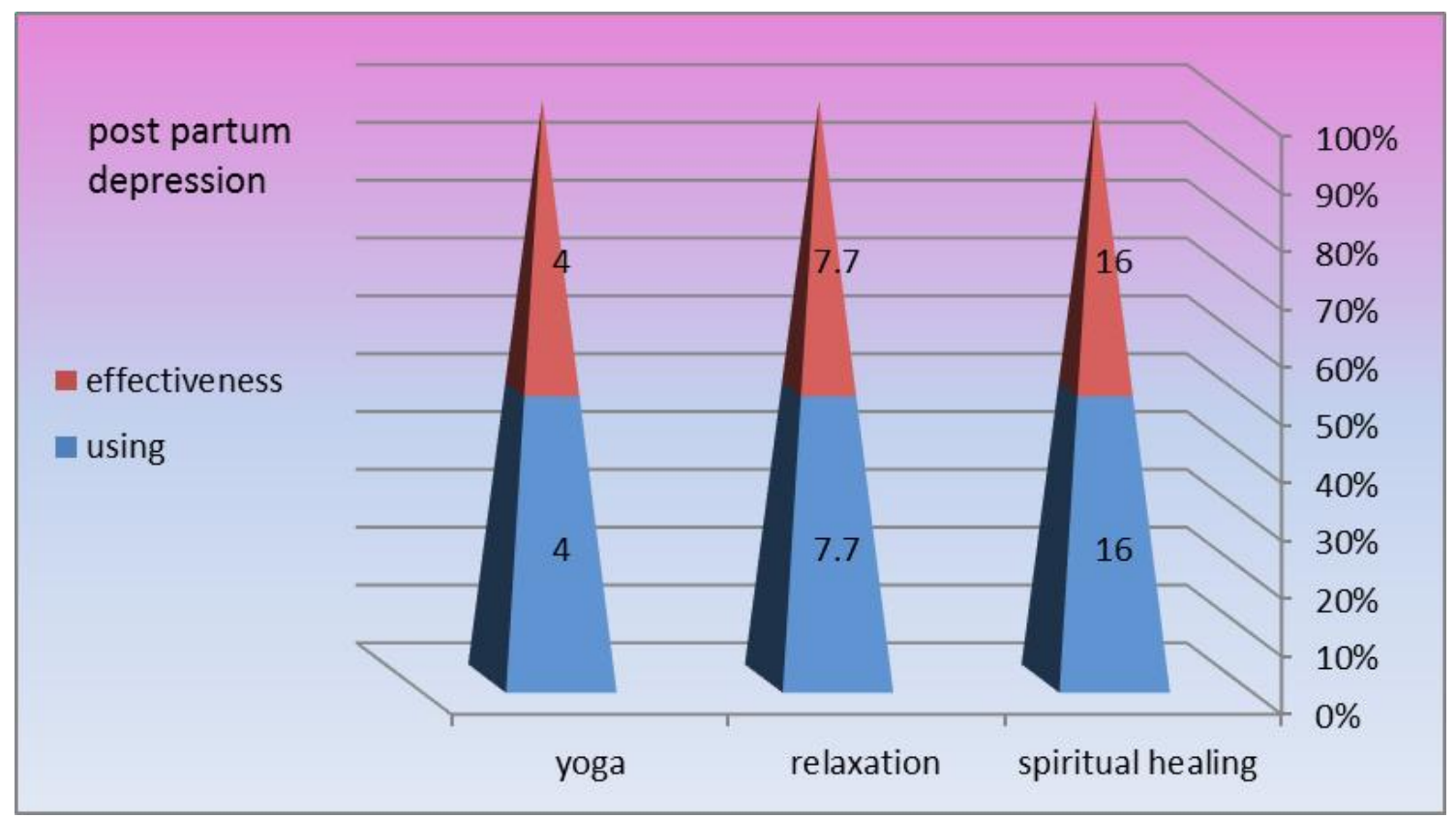

Figure (5): Types of CATs that are used by nurses to cope with postpartum depression

Table (7): Nurses' Attitudes towards Complementary/ Alternative Therapies ( $\mathrm{N}=90)$.

\begin{tabular}{|l|c|c|}
\hline \multicolumn{1}{|c|}{ Positive attitude towards: } & Frequency & Percent \\
\hline Applications & 56 & 62.2 \\
Nurse role & 68 & 75.6 \\
Effectiveness & 46 & 51.1 \\
\hline Total attitude: & & \\
Agree (Positive) & 61 & 67.8 \\
Disagree (Negative) & 29 & 32.2 \\
\hline
\end{tabular}

\section{DISCUSSION:}

Dekeyser and Wagner (2001) had done a study about knowledge levels and attitudes of staff nurses towards CATs. She had reported that slightly more than three quadrants of her subjects had knowledge about CATs, and this incongruent with the current study.

More than one third of the studied nurses had obtained their information from their relatives and friends or the mass media. This was expected since Egyptian women when feel sick or unwell, they will ask their mothers and /or friends about what they can do/use to cope with their problem. They always depend on the successful experience of significant others. 
The above mentioned finding goes in line with Furlow et al., (2008) study about physicians and patients attitudes towards complementary and alternative medicine in obstetrics and gynecology. They reported that the main sources of patient's information were family and friends, and the least source was the specialist. They also found that most patients did not consult a professional health care provider before using the CATs because the health care provider is not keen to discuss this matter with them. Moreover, most of the studied nurses asked for a training course about CATs to be conducted with a specialist in this area..

Regarding nurses' awareness and utilization of CATs, the current study revealed that the majority of nurses were self-practiced some types of CATs. These include; herbal therapy, honey and bee products, spiritual healing and massage despite their insufficient knowledge about them. Here nurse's customs and cultural traditions play a sizeable role in coping with their problems. They sometimes depend on the successful experience of significant others in managing their common frequent healthy complaints, so they practiced CATs as types of traditional therapies they are used to and trusted.

More than one fourth of nurses were self-practiced CATs many times and more than half of them sometimes used such therapies but more than three fifth never advice their patients about CATs. This may be related to the common trend that the role of the nurse is just to implement medical orders and give the prescribed medication.

A partial contradicting finding was reported by Xue et al., (2008) study in Hong Kong about nurses' utilization of CATs. They reported that the majority of their subjects had used at least one form of CATs, where they had used it either for themselves or their patients. Also, Fran et al., (2005) study about the use of CATs among the American Critical-Care Nurses reported that most of their sample was using one or more CATs for their patients in their practice. This was based on their- believe that CATs use is legitimate and beneficial to patients' welfare. They further attributed the nurses' use of CATs to their academic preparation which had included courses about CATs uses (Tracy, 2005).

In relation to the reasons given by nurses about their utilization of CATs, the current study showed that, the most common reason was their- believe that CATs would be better in some cases than traditional medicine, followed by their availability and effectiveness. This finding is in accordance with Abdul-Aziz et al, (200) who reported that the avoidance of exposure to medical therapies and their side effects, the presence of chronic conditions 
that are probably not yielding to traditional medical treatment, the availability of evidence in the literature about the safe and effective use of some CATs are some reasons of wide spread of CATs use.

Regarding to the utilization and effectiveness of CATs in management of some disorders related to Obstetrics and gynecology, the present study revealed that more than three quarters of nurses had used CATs for relief of dysmenorrhea and almost the same percentage found them effective. Meanwhile, few number of nurses used CATs in the treatment of vaginitis and menopausal symptoms (e.g., hot flashes, insomnia and headache). Almost three quarters of nurses used CATs for the management of dysmenorrhea. Herbal components as peppermint and anise were the most common and they found that they were effective in the relief of menstrual pain.

This finding is supported by Tiran, (2003) who reported that cinnamon has excellent antispasmodic or spasmolytic action, which is due to the presence of cinnamaldehyde. So it is used for management of colic or pain including dysmenorrhea. Also it is in line with (Abdul-aziz et al, 2003) who mentioned that herbals teas like anise and chamomile can help to relieve the menstrual pain. Furthermore, Saber (2008), had also stated that the tea of peppermint leaf mixed with chamomile can be used for more effective relieve of menstrual pain.

As regards to menopausal symptoms e.g. hot flashes, insomnia and headache the most common herbals used by the study subject were anise (yansoon) and tilio. This agrees with Somekawa et al., (2001) who reported that anise was used as a cure for sleeplessness and it has a sedative, antispasmodic and aromatic action.

The present study finding revealed that more than one- fifth of the subjects had used massage and nigella oil for management of back pain .Massage can help relax tense muscles and relieve aches and pains. Treatment with essential oils can often help relieve the painful muscle spasms that contribute to back pain. This result goes in line with annual report of internal medicine (2007), about the non-pharmacologic options for the treatment of low back pain, who found that $65 \%$ of primary-care physicians recommended massage therapy to their patient (Chou and Huffman, 2007).

Nurses in the present study used peppermint and ginger to relief the morning sickness and found that they were effective. Such finding is in agreement with the recent report of the George Mateljanfoundation, (2014) who found in the six double-blind, randomized controlled trials with a total of 675 participants, that ginger is effective in relieving the severity of nausea and vomiting during pregnancy. This review also 
confirmed the absence of significant side effects or adverse effects on pregnancy outcomes. Ginger's anti-vomiting action has been shown to be very useful in reducing the nausea and vomiting of pregnancy, even most severe form, and hyperemesis gravidum.

The present study also showed that nurses used fenugreek, anise and few of them drink moughat to cope with the problem of insufficient milk from the breast. Similarly, Tiran, (2003) reported that the use of fenugreek significantly increased the volume of breast milk. However fenugreek may be not right for everyone since the herb has caused aggravated asthma symptoms in some women and has lower blood glucose levels in other women with diabetes. As for the intake of moughat, it is considered the most traditional beverage during postpartum period among Egyptian women. Post-partum women are advised by their care givers to consume a minimum of 2-3 glasses of moughat daily. It is a herbal plant, high in calories due to its content of carbohydrates, fat, saccharine and minerals. moughat beverage in Egypt is prepared by mixing moughat powder with sugar and ghee to make it tastier (Ismail, 2007).

\section{CONCLUSION:}

\section{Based on study findings, it can be concluded that:}

The majority of nurses had unsatisfactory knowledge about CATs definition, types and side-effects. The nurses' source of information was mostly from their relatives and friends. Meanwhile, they stated that they wished to have training course to be conducted for them by CATs specialist. The most common reasons for their using to CATs are believing that the actions, availability and effectiveness of CATs are better in treating some problems than traditional medicine. The majority of nurses agree that CATs is a part of nurse's role, totally they had positive attitude towards the use of CATs.

\section{RECOMMENDATIONS:}

\section{From the above conclusion, the following recommendations are suggested:}

- Academic preparation of maternity nurses should be regularly updated through incorporation of CATs within their curricula

- Types of CATs with evidence based practices should be available for nurses working in maternity and gynecological field to use them and assess their effectiveness.

- Researches about CATs should be encouraged among maternity nurses to evaluate their effectiveness and risks in their field.

- Instructional brochures about using credited types of CATs should be provided in maternity and child health centers.

- A training program is essential for maternity nurses to upgrade their knowledge and practice to provide quality care to women regarding CATs. 
- Barriers against the utilization of CATs among the maternity and gynecological nurses need to be investigated.

\section{REFERENCES:}

Abdel-Aziz K., Ahmed S. (2005): utilization of complementary and alternative medicine among Arab Emirates university student. Available at: http://www.Biomedcentral.com/1385-655/8/3/abstract. Retrieved on: 10 February 2008.

Allaire A. and Wells S. (2007): Complementary and Alternative medicine in pregnancy: a survey of North Carolina certified nurse-midwives. Obstetric \&Gynecoogy; 95(1): 1923.

Bishop F. andLewith G. (2010): Who uses CAM? A narrative review of demographic characteristics and health factors associated with CAM use. Evidence Based Complementary and Alternative Medicine; 11 - 28 (1): 11- 28.

Braun L. and Cohen M. (2007): introduction to complementary medicine. Herbs \& natural supplement: an evidence based gide. $2^{\text {nd }}$ ed. Sydney: Elsevier; P 1- 13.

Frances M. (2011): Energy Medicine. Practical Application of Ancient wisdom. Available at: http://www.intutionmedicine.com/ academy/ classes. htm. retrieved on $\underline{09 / 05 / 2008}$.

Saber A. (2008): Knowledge, utilization and altitudes of maternity and gynecological nurses toward complementary and alternative therapies. University of Alexandria. Faculty of nursing. Egypt. Unpublished master thesis.

The National Center for Complementary and Alternative Medicine (NCCAM)(2008): Biologically based practices: an overview.Lastmodified 1 Decmber 2008. Available at URL: http://nccam.nih.gov/ health/ backgrounds/mindbody.htm.retrived on 8/12/2008

Uzun O. and Tan M.(2004): Nursingstudent's opinions and knowledge about complementary and alternative medicine therapies. Complementary Therapies in Nursing and Midwifery; 10(4): 239-44.

Wang S., Dezinno P., Fermo L., WilliamK., Caldwell-Andrews A., Bravemen F., et al.(2005): Complementary and alternative medicine for low-back pain in pregnancy: a cross-sectional survey. The journal of Alternative and Complementary Medicine; 11(3): 459- 64. 


\section{إدراك ممرضات أمراض النساء والتوليد تجاه العلاجات التكميلية والبديلة}

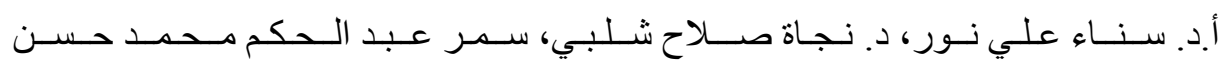

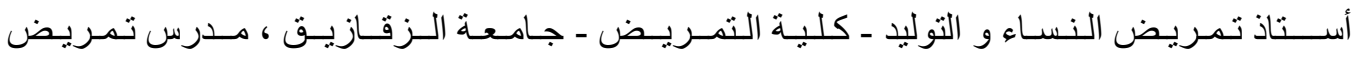

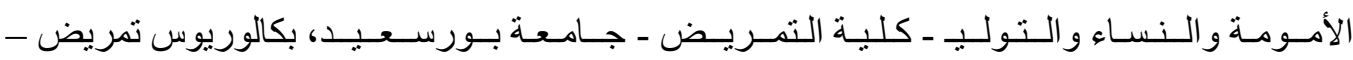

$$
\text { جامعـة المنصـورة }
$$

\section{الـخـلاصـــة}

العلاجات التكميلية والبديلة الآن من الموضوعات التي تتصدر الساحة حيث يزداد عدد المرضي الذين يفضلون استخدامها في كل بلاد العالم. ومن الملاحظ أن النساء، وخاصة اللاتي في سن الإنجاب هن أكثر استخداما لها من لهن الرجال ولذلك يتطلب الاستخدام المتز ايد من قبل النساء لهذه العلاجات أن يتم تزويد الممرضة بالعلوم و التطبيقات

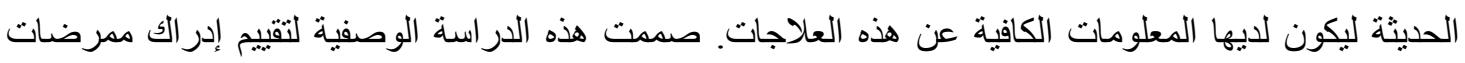
أمر اض النساء و التوليد تجاه العلاجات التكميلية والبديلة. وقد أجريت هذه الدراسة في مدينة المنصورة في أقسام

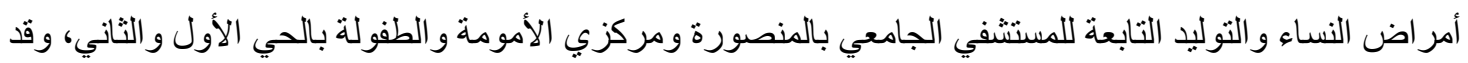

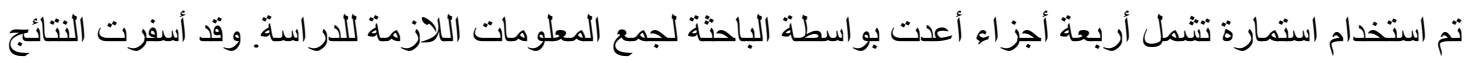

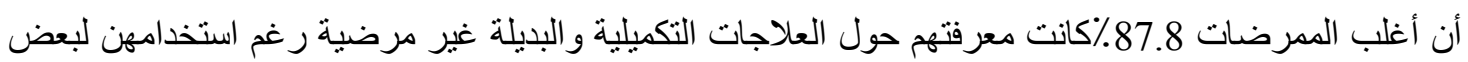
أنو اعها كالعلاج بالأعشاب. وكانت الممرضات اللاتي لديهن موقف إيجابي تجاه العلاجات التكميلية و البديلة حو الي التلثين 67.8٪، لذلك أوصيت هذه الدر اسةـ بأن الإعداد الإكاديمي لممرضي أمر اض النساء و التوليد لابد أن يأخذ في لهاه الاعنبار إدراج العلاج البديل و التكميلي في مناهجهم الدراسية. 